Document downloaded from:

http://hdl.handle.net/10251/65635

This paper must be cited as:

Jordá Vilaplana, A.; Sánchez Nacher, L.; García Sanoguera, D.; Carbonell Verdú, A.; Ferri Azor, JM. (2016). Effects of aging on the adhesive properties of poly(lactic acid) by atmospheric air plasma treatment. Journal of Applied Polymer Science. 133:1-9. doi:10.1002/app.43040.

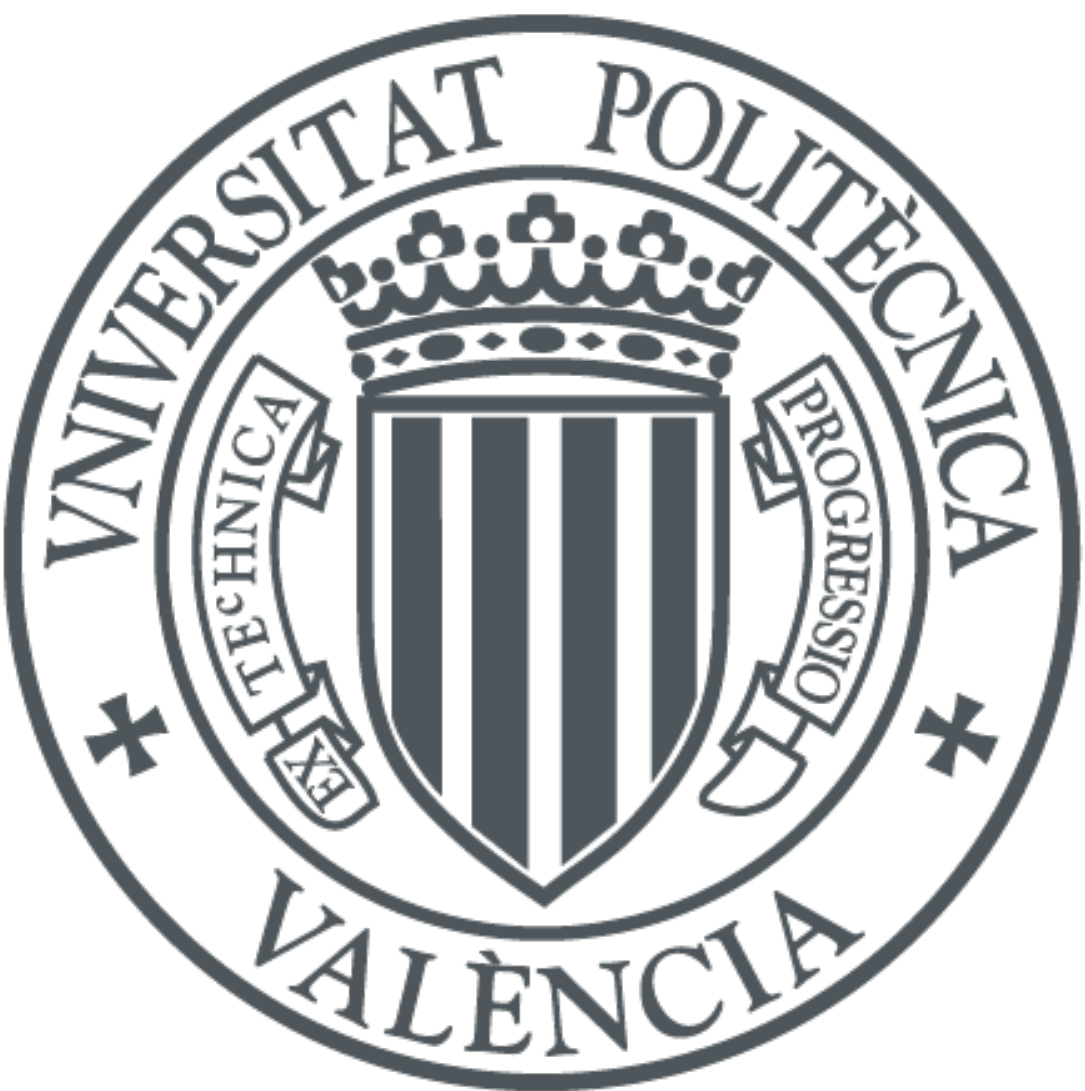

The final publication is available at

http://dx.doi.org/ 10.1002/APP.43040

Copyright Wiley-Blackwell

Additional Information 


\title{
EFFECTS OF AGING ON ADHESIVE PROPERTIES OF POLY(LACTIC ACID) (PLA) BY AIR ATMOSPHERIC PLASMA TREATMENT
}

\author{
${ }^{a}$ Jordá-Vilaplana A, ${ }^{b}$ Sánchez-Nácher $L,{ }^{b}$ García-Sanoguera $D,{ }^{b}$ Carbonell A, ${ }^{b}$ Ferri JM \\ ${ }^{a}$ Departamento de Ingeniería Gráfica (DIG) Teléfono:+34966528451 amjorvi@upv.es \\ Universitat Politècnica de València (UPV), 03801, Alcoy (Spain) \\ ${ }^{b}$ Instituto de Tecnología de Materiales (ITM) \\ Universitat Politècnica de València (UPV), 03801, Alcoy (Spain)
}

\begin{abstract}
The aim of the present work is to analyse the durability of plasma treatment on the polylactic acid (PLA) surface. We have used atmospheric plasma treatment with air in order to improve the wettability of PLA, by evaluating the aging effect under controlled conditions of relative humidity $(\mathrm{RH})$ and temperature $\left(25 \% \mathrm{RH}\right.$ and $\left.25^{\circ} \mathrm{C}\right)$.

The durability of the atmospheric plasma treatment was studied by measurements of contact angle, surface energy calculation and the change in resistance of the adhesive bonds PLA / PLA. These techniques allow to evaluate the recovery phenomenon hydrophobic PLA surface suffers from the effect of aging. The results provide the maximum storage time of PLA treated with atmospheric plasma, so this keeps its good adhesion properties, this time is lower than 3 days of storage at normal atmospheric conditions.
\end{abstract}

\section{Introduction.}

One of the most interesting biopolymer on researching fields is polilactic acid (PLA). There is an increasing demand of this kind of polymer due to the renewable origin of the raw material for its production and also because of its biodegradable properties. PLA is the second produced bioplastic in big scale preceded by starch. [1, 2],[3] [4, 5], [6, 7] 
Packaging is the industrial field in which PLA is the most demanded polymer, mainly for short-life products. PLA is satisfactorily replacing traditional "commodities" polymers for these applications. Main features of this biopolymer are the high mechanical strength, transparency and processability. PLA is formed by polyester and $100 \%$ renewable material produced from lactic acid. On the other hand, lactic acid is produced by anaerobic fermentation of substrates with carbon, either pure (glucose, lactose, etc.) or impure (starch, molasses, etc.) with microorganisms like bacteria Lactobacillus, Pediococcus, Lactococcus and Streptococcus, or some fungus like Rhizopus Oryzae. Industrially saccharose coming from sugar cane and beet is used, along with glucose. [8, 9] [10, 11] [12-14]

Nowadays packaging is one of the most demanded sectors of PLA, mainly for short-life products like disposable dishes, glasses, straws, feeding bags, films, cosmetic containers, etc... Design is a very important factor in packaging sector and, in most of them, adhesion is needed. Due to intrinsically low surface humidity in polymer, is pretended to improve the surface hydrophilicity on the substrate. To achieve it, a technology of surface modification based on atmospheric plasma is used. This technology is a really versatile technology because vacuum is not needed, furthermore is adaptable to automatic production and capable to work in continuous in a production line and because of its lack of waste, we are in front of an environment friendly process. This treatment of surface modification increases resistant properties of adhesive unions on polymeric surface treated, because of the enhancement of the wettability of these. The effect of atmospheric plasma surface treatment over polymeric surfaces is an important surface activation which increases polymer surface energy and therefore its hydrophilicity. These allow a better adhesive/polymer interaction, improving adhesion. But these surface activation effects are not permanent, and the enhancement on the surface wettability decreases along the time. This aging phenomenon is called hydrophobic recovery.[15-17] [18] [19]

Regarding to the atmospheric plasma on PLA surface, the plasma treatment promotes an increase on surface energy of $59 \%$ from values around $37.10 \mathrm{~mJ} \mathrm{~m}^{-2}$ to values close to $58.92 \mathrm{~mJ}$ $\mathrm{m}^{-2}$. This is due to the atmospheric plasma treatment on PLA surface, induces the appearance of 
new activated species, like carboxyl (-COOH), carbonyl (-CO), hydroxyl (-OH), peroxyd (ROOR-), hydroperoxid (-ROOH), eter (-COC-), ester (-COOC-) and other functional groups which change along the time to achieve stable tate. [20] [21, 22] [22-26] This eductions of active groups acts negatively on the wettability properties achieved with treatment. The main actuating mechanism of the atmospheric plasma surface treatment is the chemical functionalization of the treated surface, so it is important to determine the durability of the treatment and quantify changes of wettability along the time, causing an aging process. $[15,17$, $27,28][16,23][29,30]$

In this paper, the effect of the time after the atmospheric plasma treatment over PLA substrate has been evaluated. Process aging conditions were: $25 \% \mathrm{RH}$ and $25^{\circ} \mathrm{C}$ for 21 days, usual conditions in industrial. Furthermore, hydrophobic recovery phenomenon is determined on PLA/PLA union resistance depending on the aging time. In these unions, a biodegradable adhesive is used to maintain an eco-friendly character of the study. It is important to take into acount the aging factor to implant this technology in an industrial process, because it affects to the storage time of the product waiting for a post-process. Determine the maximum storage of PLA samples by analysing the hydrophobic recovery process will be require in order to optimize the industrial process in terms of adhesion. [31-36]

\section{Experimental.}

\subsection{Material and Sample Preparation}

Polylactic acid (PLA) commercial grade PLA 6201D was supplied in pellet form by Nature Works LLC (Nature Works LLC, Minnetonka, Minnesota, USA). Material was injected in a gloss mirror finish of dimension $(160 \times 60 \times 2.2) \mathrm{mm}^{3}$ in the manufacturer recommended conditions.

Four different liquids were used for contact angle measurements and subsequent surface energy calculations. The liquids are: stabilized diiodomethane with $99 \%$ of purity and supplied 
by Acros Organics (Acros Organics, Geel, Belgium), double distilled water, formamide and glycerol 99\%, extra pure for analysis (reagent grade) ACS from Scharlau Chemie S.A. (Scharlab S.L. Barcelona, Spain).

These test liquids were selected to cover a wide range of polar $\left(\gamma_{\mathrm{s}}^{\mathrm{p}}\right)$ and dispersive $\left(\gamma_{\mathrm{s}}^{\mathrm{d}}\right)$ components of the total liquids surface energy $\left(\gamma_{\mathrm{s}}\right)$ shown in Table I.

Table I

A commercial adhesive grade EcoPoxy Fast Hardener supplied by Ecopoxy Systems Company (Providence, EEUU) was used to form PLA-PLA adhesion unions. Ecopoxy is a partially biobased adhesive with epoxidized soybean oil and it finds typical applications as polymer adhesive.

\subsection{Atmospheric plasma surface treatment}

PLA samples were subjected to atmospheric plasma treatment using a plasma generator, "Plasma JetRD1004" model, provided by Plasmatreat GmbH (Steinhagen, Germany). The plasma generator works at 50/60 Hz, $230 \mathrm{~V}$ and $16 \mathrm{~A}$, with frequency of $17 \mathrm{kHz}$ and a discharge voltage of $20 \mathrm{kV}$. The plasma treatment was applied using a rotating torch ending in a nozzle with a rotation speed of $1900 \mathrm{rpm}$.

Atmospheric plasma was applied with a nozzle-sample distance of 6 and $10 \mathrm{~mm}$. The treatment rate was set in the 100,300 and $700 \mathrm{~mm} \mathrm{~s}^{-1}$. The samples used were $60 \times 20 \times 2.2 \mathrm{~mm}$ in size. 


\subsection{Aging}

Durability of the atmospheric plasma surface treatment has been studied through catching surface contact angle measurement for different storage times (from 3 hours to 21 days). The storage conditions of PLA samples were $25^{\circ}$ and $25 \%$ relative humidity.

\subsection{Contact angle and surface energy}

An Easydrop Standard equipment, model FM140 supplied by KRÜSS (Hamburg, Germany), has been used to measure contact angle. The maximum error in the contact angle measurement did not exceed $\pm 3 \%$. The software used is DROP SHAPE ANALYSIS SW21 (DSA1). This process was realized with 4 different test liquids, with different polarities, in order to calculate the surface energy.

Owens-Wendt method has been used to calculate the surface energy. This method is able to determine both additive contributions: disperse and polar. The expression [1] represents the equation for surface energy calculation.

$$
y_{1} \cdot(1+\cos (\theta)) / 2\left(y_{1}^{d}\right)^{1 / 2}=\left(y_{s}^{p}\right)^{1 / 2} \cdot\left[\left(y_{1}^{p}\right)^{1 / 2} /\left(y_{1}^{d}\right)^{1 / 2}\right]+\left(y_{s}^{d}\right)^{1 / 2}
$$

Where $\theta$ is angle contact, $y_{1}$ is the surface tension of the liquid and $y_{s}$ is the surface tension of the solid or free surface energy. $d$ and $p$ terms refers to dispersive and polar components of each phase respectively. This expression is plotted linearly, being equivalent to $y=a x+b$. If $\left(y_{1}^{p}\right)^{1 / 2} /\left(Y_{1}^{d}\right)^{1 / 2}$ is represented versus $y_{1} \cdot(1+\cos (\theta)) / 2\left(y_{1}^{d}\right)^{1 / 2}$ a linear interception of this line on the axis. The slope of the line gives $\left(Y_{s}^{p}\right)^{1 / 2}$ while $\left(Y_{s}^{d}\right)^{1 / 2}$ is the intersection of the beeline with $Y$ axis. The sum of $y_{s}^{d}$ and $y_{s}^{p}$ is the surface free energy $\left(y_{s}=y_{s}^{p}+y_{s}^{d}\right)$.

\subsection{Mechanical characterization}

The test used to evaluate PLA/PLA adhesive joints strength was the determination of shear strength by the block-shear method, following standard ISO 13445. Five samples of $25 \times 25 \times 2$ 
$\mathrm{mm}$ in size, with adhesive joints from 10 to $12 \mathrm{~mm}$, of each treated surface, were subjected to a shore rate of $300 \mathrm{~mm} \mathrm{~m}^{-1}$ in an IBERTEST ELIB 30 (Ibertest SAE. Madrid, Spain), at room temperature.

\subsection{Infrared Thermography (IR)}

To evaluate the effect of the plasma treatment on the PLA surface in terms of degradation caused by high temperature, a thermal vision camera IR 980 supplied by CANTRONIC Systems Inc. (Coquillan, Canada) was used. The dispositive allows to obtain thermal images in the range of temperatures -20 to $600{ }^{\circ} \mathrm{C}$ with a precision of $\pm 5{ }^{\circ} \mathrm{C}$

\section{Results and discussion.}

\subsection{Aging on the polylactic acid (PLA) treated by atmospheric plasma.}

An aging study of PLA substrate was realized to determine the treatment durability before the atmospheric plasma treatment. This study consists on taking measurements of the contact angle, on the PLA substrate using 4 different contact liquids with different polarities for different samples with storage time from 0 hours to 21 days, at $25^{\circ} \mathrm{C}$ and $25 \%$ RH. .[37] [38, 39] $[40,41]$

In previously works about the effects of atmospheric plasma effect on PLA surface, was concluded that low treatment rates and short distances between nozzle and the substrate were the most effective. Here by, in this study distances of 6 and $10 \mathrm{~mm}$ and treatment rates of 100 , 300 and $700 \mathrm{~mm} \mathrm{~s}^{-1}$ were chosen to quantify the hydrophobic recovery on the PLA polymeric substrate. [20]

Table II

In table II, a summary of the contact angle results for different aging times are shown. For each analyzed treatment rates, the increasingly trend on the contact angle is observed for a distance of $6 \mathrm{~mm}$. No significant changes on contact angle are observed at low storage time. Then, an increase on contact angle is observed during 21 aging test days. This effect is produced because 
of the realignment and disappearance of the unstable species generated by the atmospheric plasma treatment over the substrate, reducing surface polarity and subsequent wettability of the PLA, and these effects were quantified because of the increasing on the contact angle.[23, 42, 43] [44] [27]

Quantifying the loss of surface wettability, with increases on the contact angles, can be observed for water liquid that for: 5 days after the treatment, and treatment rate of $100 \mathrm{~mm} \cdot \mathrm{s}^{-1}$ a11\% of increasing on the angle is produced. An increase of $5 \%$ on the angle is observed for higher treatment rates, 300 and $700 \mathrm{~mm} \cdot \mathrm{s}^{-1}$. After 21 days of storage time, water contact angle increases up to $56 \%, 37 \%$ and $17 \%$, for treatment rates of 100,300 and $700 \mathrm{~mm} \cdot \mathrm{s}^{-1}$. Respectively, a lower angle is observed on treated PLA than in non-treated when 21th day is reached. This corroborate that although there is a loss of wettability because of the loss of surface functionalization of the PLA caused by the action of the atmospheric plasma initially, this treatment not only a chemical modification but also produces a etching of the surface material. This causes an increase in the substrate wettability due to the physical modification that does not change along the aging time. [4, 45] [44] [46] [27, 47, 48]

\section{Table III}

In Table III can be observed a summary of obtained values of contact angles for samples treated with different rates and nozzle-substrate distance, with different storage times. An increase on contact angle is observed along aging time in treatment conditions of $10 \mathrm{~mm}$ and for all treatment rates used.

For treatment conditions of $10 \mathrm{~mm}$ and $100 \mathrm{~mm} \mathrm{~s}^{-1}$, a significant hydrophobic recovery in the hours after the plasma treatment is shown in Table III. Only after 3 hours after treatment, the increase in the value of the contact angle of water is $29 \%$, which is indicative of a fast recovery hydrophobic. This marked increase in contact angles is because in these conditions of application of plasma treatment (optimum condition, according to previous studies) the 
maximum surface activation or polarity was achieved. Precisely because of the chemical instability of these active species react quickly to more stable states with the same atmosphere, and quickly lose their functionality when presenting higher values in the contact angle. After 21 days of atmospheric aging, taking water as reference, the contact angle on the surface of PLA increased by $56 \%$ under low treatment rates. An increase on the contact angle of $37 \%$ and $17 \%$ for 300 and $700 \mathrm{~mm} \mathrm{~s}^{-1}$ respectively is produced with high treatment rates.[42, 43]

A marked hydrophobic recovery is shown on treated PLA, this hydrophobic recovery is more accentuated on the first aging time hours. After analysing the evolution of contact angle for 21aging days in a PLA sample, the variation of the surface energies during the same aging period were studied. $[49,50][51,52]$

Figure 1

Figure 1 shows the variation of the total surface energy $\left(\gamma_{s}\right)$, their polar contributions $\left(\gamma_{s}{ }^{p}\right)$ and dispersive $\left(\gamma_{s}{ }^{d}\right)$ in front of air aging time, for treated PLA with distance of $6 \mathrm{~mm}$ and different treatment rates.

A decrease on the variation of the surface energy, mainly on the polar component $\left(\gamma_{s}{ }^{p}\right)$, for the 21 aging days under storage conditions is shown due to the restructuring of the active species on the PLA surface sample treated with atmospheric plasma. This surface energy decrease up to $28 \%$ at 21 days for treated samples with $6 \mathrm{~mm}$ of distance and $100 \mathrm{~mm} \cdot \mathrm{s}^{-1}$ of treatment rates. In the same conditions, polar component decreases to a value of $9.47 \mathrm{~mJ} \mathrm{~m}^{-2}$ close to that obtained without treatment, $6.79 \mathrm{~mJ} \mathrm{~m}^{-2}$. However, the dispersive component have a slightest variation, remaining in the $26-33 \mathrm{~mJ} \cdot \mathrm{m}^{-2}$ range.

For $300 \mathrm{~mm} \cdot \mathrm{s}^{-1}$ of treatment rate, the decrease on surface energy after the aging process is about $25 \%$, and by $15 \%$ for $700 \mathrm{~mm} \cdot \mathrm{s}^{-1}$. Polar component $\left(\gamma_{\mathrm{s}}^{\mathrm{p}}\right)$ decreases from $17.51 \mathrm{~mJ} \cdot \mathrm{m}^{-2}$ of non-aging sample to $6.78 \mathrm{~mJ} \cdot \mathrm{m}^{-2}$ of $300 \mathrm{~mm} \cdot \mathrm{s}^{-1}$ treatment rate. At high treatment rates, 700 $\mathrm{mJ} \cdot \mathrm{m}^{-2}$, polar component $\left(\gamma_{\mathrm{s}}{ }^{\mathrm{p}}\right)$ decreases from $12.37 \mathrm{~mJ} \cdot \mathrm{m}^{-2}$ to $7.23 \mathrm{~mJ} \cdot \mathrm{m}^{-2}$ after 21 days of 
atmospheric aging. A higher realignment of polar modules inserted and activated on the polymer surface during the atmospheric treatment is promoted with increasing on aging time. $[53,54]$

Figure 2

Figure 2 shows the variation on the total surface energy $\left(\gamma_{s}\right)$, their polar contributions $\left(\gamma_{s}{ }^{p}\right)$ and dispersive $\left(\gamma_{s}{ }^{d}\right)$ regarding air aging time, for PLA atmospheric plasma pre-treated samples with distance of $10 \mathrm{~mm}$ and different treatment rates.

Decreases obtained on the surface energy after 21 days of aging are: $36.7 \%, 28.7 \%$ y $18 \%$ for treatment rates of 100,300 y $700 \mathrm{~mm} \cdot \mathrm{s}^{-1}$ respectively. This lower surface energy is mainly due to the loss of polarity of PLA treated with plasma. Polar component $\left(\gamma_{S}^{p}\right)$ of the surface energy also presents a clear decrease. For $100 \mathrm{~mm} \cdot \mathrm{s}^{-1}$ the polar component $\left(\gamma_{\mathrm{s}}^{\mathrm{p}}\right)$ decreases from $32.83 \mathrm{~mJ} \cdot \mathrm{m}^{-2}$ to $6.92 \mathrm{~mJ} \cdot \mathrm{m}^{-2}$ after 21 days of storage. For higher treatment rates, 300 and 700 $\mathrm{mm} \cdot \mathrm{s}^{-1}$, this decreases from $26.24 \mathrm{~mJ} \cdot \mathrm{m}^{-2}$ to $8.14 \mathrm{~mJ} \cdot \mathrm{m}^{-2}$; and from $20.49 \mathrm{~mJ} \cdot \mathrm{m}^{-2}$ to $6.81 \mathrm{~mJ} \cdot \mathrm{m}^{-2}$, respectively.

High polarity or functionalization, generated by atmospheric plasma, causes a fast reaction of the active species on PLA surface with air elements, in the aging process, by this way polar component values decreases $\left(\gamma_{s}^{\mathrm{p}}\right)$ mainly in the first hours after the plasma treatment. After 21 aging days both surface energy $\left(\gamma_{\mathrm{S}}\right)$ as its polar component $\left(\gamma_{\mathrm{S}}{ }^{\mathrm{p}}\right)$ and dispersive $\left(\gamma_{\mathrm{S}}{ }^{\mathrm{d}}\right)$ can reach values close to untreated sample.

Aging process is closely related with the instability of the polar species generated on the surface treated with atmospheric plasma treated surface, and is the result of the continuous chemical reactions suffered by free radicals generated on the surface by plasma treatment, with the oxygen and humidity existing in the environment. Also free rotation of hydrophilic polar groups into the PLA structure, which reduces on the surface wettability. [38, 39] [52, 55] 


\subsection{Variation on the PLA adhesive properties on the aging process}

The effect of the aging of PLA $n$ their adhesive properties was quantified using plasmatreated PLA sheets join by using a commercial adhesive. This study is realized to optimized process conditions of the plasma in two distances: $6 \mathrm{~mm}$ and $10 \mathrm{~mm}$; in three treatment rates: 100,300 and $700 \mathrm{~mm} \cdot \mathrm{s}^{-1} \cdot[49][56][57]$

Previously, the optimal cured time of the bio-adhesive used is determined experimentally. Maximum strength of the PLA/PLA adhesion joints on shear stress is represented on table IV, for surface conditions of PLA: with and without atmospheric plasma treatment at $6 \mathrm{~mm}$ between PLA surface and plasma nozzle, and $100 \mathrm{~mm} \cdot \mathrm{s}^{-1}$ of treatment advance rate.

\section{Table IV}

A progressive increase on the maximum adhesive strength is observed for the untreated surface to reach a maximum of $50.63 \mathrm{Ncm}^{-2}$ for 90 minutes of curing. For higher times, strength values remain almost constant. A similar effect is observed on atmospheric plasma treatment samples. Maximum strength value of the adhesion joint, $150.10 \mathrm{Ncm}^{-2}$ is obtained for curing times of 90 minutes. There is no enhancement on the adhesion joint strength for higher cured times, insomuch as ranks are maintained on $150-149 \mathrm{~N} \mathrm{~cm}^{-2}$ for times of 180 minutes. So, an optimal curing time is see to 90 minutes for later tests.

Once the optimal curing time of bio-adhesive time has been determined, the effect of aging time over PLA/PLA adhesion joint is analyzed. Figure 3 shows the variation on maximum strength of PLA/PLA adhesion joints as a function of aging time. For atmospheric plasma treated samples with a nozzle/substrate distance of $6 \mathrm{~mm}$ and a different treatment rates (100, 300 and $700 \mathrm{~mm} \cdot \mathrm{s}^{-1}$ ). As it can be observed, the shear strength decrease with the aging time, this fact corroborates the variation of the surface energy with the aging time described previously.

Figure 3 
By this way, for a treatment rate of $100 \mathrm{~mm} \mathrm{~s}^{-1}$ the shear strength obtained immediately after the atmospheric plasma treatment is $150.03 \mathrm{~N}$. After 6 aging days, there is a loss on the maximum strength in the adhesion joint of $15 \%$, which reaches $53 \%$ for 21 days. However, at the finish of analyzed period, maximum strength is higher than plasma untreated PLA/PLA adhesion joint, $50.10 \mathrm{~N} \mathrm{~cm}^{-2}$. For higher plasma treatment rates on the PLA surface $\left(300 \mathrm{~mm} \mathrm{~s}^{-}\right.$ $\left.{ }^{1}\right)$ maximum strength value is $133.50 \mathrm{Ncm}^{-2}$. After 21 aging days, maximum shear strength decrease to $73.05 \mathrm{Ncm}^{-2}$, a $45 \%$. For rates of $700 \mathrm{~mm} \cdot \mathrm{s}^{-1}$, this decrease is about $60 \%$.

Figure 4 plots maximum adhesive PLA/PLA adhesion strength during aging time, for plasma treated PLA with a distance of $10 \mathrm{~mm}$ and different rates $\left(100,300\right.$ and $\left.700 \mathrm{~mm} \mathrm{~s}^{-1}\right)$. In the same way of the previous case, there is a trend on the decrease of the maximum strength with aging time.

Figure 4

Comparing experimental results for different treatment rates, there are always a loss of the maximum adhesion strength with the aging time.

In conditions of $10 \mathrm{~mm}$ PLA/nozzle distance, maximum shear strength is obtained for low treatment rate, $100 \mathrm{~mm} \cdot \mathrm{s}^{-1}, 168.7 \mathrm{Ncm}^{-2}$ in PLA/PLA adhesion joints is obtained just immediately after plasma treatment. After 6 aging shear days, strength loss a $6 \%$ reaching $158.80 \mathrm{Ncm}^{-2}$. For higher treatment advance rates, (300 and $\left.700 \mathrm{~mm} \cdot \mathrm{s}^{-1}\right)$, maximum obtained value is $155.5 \mathrm{~N} \mathrm{~cm}^{-2}$ and $141.18 \mathrm{~N} \mathrm{~cm}^{-2}$ respectively, which decrease with aging time. At the end of the aging period analyzed (21 days), samples treated at $10 \mathrm{~mm}$ suffer a decrease of $40 \%$, $47 \%$ and $47 \%$ on maximum shear strength for rates 100,300 and $700 \mathrm{~mm} \cdot \mathrm{s}^{-1}$ respectively. In general, the study of variation of adhesive properties of PLA during atmospheric aging process has shown the negative influence of the hydrophobic recovery phenomenon of plasma treated PLA surfaces on their wettability properties. 
Nevertheless, after the aging test although there is a loss of adhesion due to the loss of wettability of the PLA surface caused by hydrophobic recovery effect, this is still higher than adhesion joint of untreated PLA for all plasma treatment conditions. After 21 aging days of the plasma treated PLA surface at $10 \mathrm{~mm}$ of PLA/nozzle distance, and for advance rates of 100, 300 and $700 \mathrm{~mm} \mathrm{~s}^{-1}$, PLA/PLA adhesion joints present values of shear strength of $50.2 \%, 39 \%$ and 33.4\% higher than untreated PLA, respectively.

Although there is an important hydrophobic recovery effect, most of the wettability achieved with atmospheric plasma is not lost entirely. As micro-etching mechanism on the PLA surface is a physical effect which increases the roughness of PLA surface, this phenomenon is not recovered during the aging time, because of that, maximum strength on plasma pre-treated PLA/PLA adhesive unions is still being higher than untreated PLA/PLA unions, even after 21 aging days. These fact corroborate the results obtained before both for the variation contact angles and the surface energy on the PLA surface as a function of aging time. On the other hand, plasma treatment with a distance PLA/nozzle of $10 \mathrm{~mm}$ provides better results.

Comparatively, maximum value on shear strength of $168.7 \mathrm{~N} \mathrm{~cm}^{-2}$ is observed from experimental results for a distance of $10 \mathrm{~mm}$ and a slow treatment rate of $100 \mathrm{~mm} \mathrm{~s}^{-1}$. This value is higher than treated samples with a distance of $6 \mathrm{~mm}$ and same treatment rate $(150.00 \mathrm{~N}$ $\mathrm{cm}^{-2}$ ). This is due to the atmospheric plasma aggressiveness in very low distances between plasma nozzle and PLA, it produces a degradation on the PLA surface that reduces the adhesion effect. On PLA surface and in general in polymer is possible to find very low molecular weight species oxidized because of the atmospheric air contact. These species can be deleted or actuate as initiators of degradation process after atmospheric plasma treatment.

A thermal camera is used to determinate if it is produced an excessive heating on the PLA surface by atmospheric plasma, and subsequent degradation. This heating can produce certain polymeric surface degradation in very short treatment times. [23, 42, 43, 58-60] 
Figure 5 and Figure 6 shows the thermal images of PLA surfaces during the plasma treatment for 6 and $10 \mathrm{~mm}$ of nozzle/substrate distance respectively. As it can be observed, a decrease on surface temperature according to the increase on the nozzle/substrate distance. Both figures are followed by a graphic where is observed a chromatic spectrum, where the variation on the colours is related with the temperature change. Blue colour, are used for low temperatures, and red colour belongs to high temperatures. Temperatures higher than $100^{\circ} \mathrm{C}$ are represented by white.

Figure 5

Figure 6

For a distance nozzle/substrate of $6 \mathrm{~mm}$, figure 5, a highest temperature of both tests are reached, with a value of $127.6^{\circ} \mathrm{C}$. Just after a decrease on the temperature is observed, reaching

$61^{\circ} \mathrm{C}$. For the same analysis at nozzle/substrate distance of $10 \mathrm{~mm}$, maximum temperature decreases significantly (33\%), in comparison with $6 \mathrm{~mm}$, reaching $84.6^{\circ} \mathrm{C}$, and immediately after that, it decreases to $50^{\circ} \mathrm{C}$ approximately.

A thermal degradation on the PLA surface is produced by high heating at low distance treatment $(6 \mathrm{~mm})$, although it is ephemeral, and has a negative influence on the surface energy values obtained in these conditions. For this reason, surface energies and shear strength of PLA/PLA adhesion joints treated with atmospheric plasma at a distances of $6 \mathrm{~mm}$ are lower than at $10 \mathrm{~mm}$.

The optimal storage time of this substrate at industrial level after the atmospheric plasma treatment will depend on the needs of the product. In the range of 3 to 6 days of storage, the adhesion strength remains in values close to $160 \mathrm{~N} \mathrm{~cm}^{-2}$, which allow the use of treated samples with improved adhesive performance. 


\section{Conclusions.}

PLA samples treated with atmospheric plasma are strongly affected by storage time. By this way, contact angle on the surface sample increases with the storage time and subsequently surface energy decreases this fact has repercussion on the loss of hydrophobicity of the PLA substrate. Low durability on the plasma effects over PLA causes an important loss on the surface wettability, which has negative repercussion on the adhesive properties of the material.

When a PLA sample is storage under typical industrial conditions, $\left(25^{\circ} \mathrm{C} ; 25 \% \mathrm{HR}\right)$ there is an important loss of surface wettability. Polar component $\left(\gamma_{s}{ }^{p}\right)$ of the surface energy is the most influential on the loss of wettability, because of the decrease of the PLA functionalization and surface activation promoted by previous atmospheric plasma treatment. The instability of polar volatile species generated on plasma treated surface, the continuous chemical reactions between free radicals generated by the plasma treatment and oxygen or humidity, and the free rotation of the hydrophilic polar groups into PLA structure, reduce surface wettability.

Variation of the strength in the adhesion joint of the PLA/PLA samples, during aging process under atmospheric conditions, shows the negative influence of the hydrophobic recovery phenomenon on the adhesive properties of the PLA. However, although there is a loss of adhesion with the aging time, the adhesion remains higher than PLA surface without plasma treatment for all conditions analysed. 


\section{References}

[1] F. Ferrero, R. Bongiovanni, Improving the surface properties of cellophane by air plasma treatment, Surf. Coat. Technol., 200 (2006) 4770-4776.

[2] E. Foldes, A. Toth, E. Kalman, E. Fekete, A. Tomasovszky-Bobak, Surface changes of corona-discharge-treated polyethylene films, J. Appl. Polym. Sci., 76 (2000) 1529-1541.

[3] J.C. Caro, U. Lappan, F. Simon, D. Pleul, K. Lunkwitz, On the low-pressure plasma treatment of PTFE (polytetrafluoroethylene) with SO2 as process gas, Eur. Polym. J., 35 (1999) $1149-1152$.

[4] C.Z. Liu, N.M.D. Brown, B.J. Meenan, Uniformity analysis of dielectric barrier discharge (DBD) processed polyethylene terephthalate (PET) surface, Appl. Surf. Sci., 252 (2006) 22972310 .

[5] C.Z. Liu, N.M.D. Brown, B.J. Meenan, Dielectric barrier discharge (DBD) processing of PMMA surface: Optimization of operational parameters, Surf. Coat. Technol., 201 (2006) 23412350 .

[6] X. Ou, M. Cakmak, Influence of biaxial stretching mode on the crystalline texture in polylactic acid films, Polymer, 49 (2008) 5344-5352.

[7] X. Ou, M. Cakmak, Comparative study on development of structural hierarchy in constrained annealed simultaneous and sequential biaxially stretched polylactic acid films, Polymer, 51 (2010) 783-792.

[8] M.A. Del Nobile, A. Conte, G.G. Buonocore, A.L. Incoronato, A. Massaro, O. Panza, Active packaging by extrusion processing of recyclable and biodegradable polymers, J. Food Eng., 93 (2009) 1-6.

[9] A.M. Harris, E.C. Lee, Heat and Humidity Performance of Injection Molded PLA for Durable Applications, J. Appl. Polym. Sci., 115 (2010) 1380-1389.

[10] A. Arora, G.W. Padua, Review: Nanocomposites in Food Packaging, J. Food Sci., 75 (2010) R43-R49.

[11] C.J. Weber, V. Haugaard, R. Festersen, G. Bertelsen, Production and applications of biobased packaging materials for the food industry, Food Addit. Contam., 19 (2002) 172-177.

[12] A.M. Harris, E.C. Lee, Improving mechanical performance of injection molded PLA by controlling crystallinity, J. Appl. Polym. Sci., 107 (2008) 2246-2255.

[13] T. Jin, H. Zhang, Biodegradable polylactic acid polymer with nisin for use in antimicrobial food packaging, J. Food Sci., 73 (2008) M127-M134.

[14] E. Mascheroni, V. Guillard, F. Nalin, L. Mora, L. Piergiovanni, Diffusivity of propolis compounds in Polylactic acid polymer for the development of anti-microbial packaging films, J. Food Eng., 98 (2010) 294-301.

[15] J. Abenojar, R. Torregrosa-Coque, M.A. Martinez, J.M. Martin-Martinez, Surface modifications of polycarbonate (PC) and acrylonitrile butadiene styrene (ABS) copolymer by treatment with atmospheric plasma, Surf. Coat. Technol., 203 (2009) 2173-2180. 
[16] C. Borcia, G. Borcia, N. Dumitrascu, Relating plasma surface modification to polymer characteristics, Appl. Phys. A-Mater. Sci. Process., 90 (2008) 507-515.

[17] L. Safinia, K. Wilson, A. Mantalaris, A. Bismarck, Atmospheric plasma treatment of porous polymer constructs for tissue engineering applications, Macromol. Biosci., 7 (2007) 315327.

[18] N.A. Bullett, D.P. Bullett, F.E. Truica-Marasescu, S. Lerouge, F. Mwale, M.R. Wertheimer, Polymer surface micropatterning by plasma and VUV-photochemical modification for controlled cell culture, Appl. Surf. Sci., 235 (2004) 395-405.

[19] M. Martinez-Martinez, M.D. Romero-Sanchez, Strategies to improve the adhesion of rubbers to adhesives by means of plasma surface modification, Eur. Phys. J.-Appl. Phys, 34 (2006) 125-138.

[20] A. Jorda-Vilaplana, V. Fombuena, D. Garcia-Garcia, M.D. Samper, L. Sanchez-Nacher, Surface modification of polylactic acid (PLA) by air atmospheric plasma treatment, Eur. Polym. J., 58 (2014) 23-33.

[21] M.D. Romero-Sanchez, J.M. Martin-Martinez, UV-ozone surface treatment of SBS rubbers containing fillers: Influence of the filler nature on the extent of surface modification and adhesion, J. Adhes. Sci. Technol., 22 (2008) 147-168.

[22] F. Teraoka, M. Nakagawa, M. Hara, Surface modification of poly(L-lactide) by atmospheric pressure plasma treatment and cell response, Dent. Mater. J., 25 (2006) 560-565.

[23] C. Cheng, L.Y. Zhang, R.J. Zhan, Surface modification of polymer fibre by the new atmospheric pressure cold plasma jet, Surf. Coat. Technol., 200 (2006) 6659-6665.

[24] N. De Geyter, R. Morent, C. Leys, L. Gengembre, E. Payen, S. Van Vlierberghe, E. Schacht, DBD treatment of polyethylene terephthalate: Atmospheric versus medium pressure treatment, Surf. Coat. Technol., 202 (2008) 3000-3010.

[25] Y.J. Hwang, S. Matthews, M. McCord, M. Bourham, Surface modification of organic polymer films treated in atmospheric plasmas, J. Electrochem. Soc., 151 (2004) C495-C501.

[26] Y.J. Hwang, Y. Qiu, C. Zhang, B. Jarrard, R. Stedeford, J. Tsai, Y.C. Park, M. McCord, Effects of atmospheric pressure helium/air plasma treatment on adhesion and mechanical properties of aramid fibers, J. Adhes. Sci. Technol., 17 (2003) 847-860.

[27] F. Xie, Q.F. Li, B. Gu, K. Liu, G.X. Shen, In vitro and in vivo evaluation of a biodegradable chitosan-PLA composite peripheral nerve guide conduit material, Microsurgery, 28 (2008) 471-479.

[28] X.M. Xie, T.R. Gengenbach, H.J. Griesser, CHANGES IN WETTABILITY WITH TIME OF PLASMA-MODIFIED PERFLUORINATED POLYMERS, J. Adhes. Sci. Technol., 6 (1992) 1411-1431.

[29] T. Jacobs, R. Morent, N. De Geyter, C. Leys, Effect of He/CF4 DBD Operating Parameters on PET Surface Modification, Plasma Process. Polym., 6 (2009) S412-S418.

[30] R. Stewart, V. Goodship, F. Guild, M. Green, J. Farrow, Investigation and demonstration of the durability of air plasma pre-treatment on polypropylene automotive bumpers, Int. J. Adhes. Adhes., 25 (2005) 93-99. 
[31] J. Balart, V. Fombuena, J.M. Espana, L. Sanchez-Nacher, R. Balart, Improvement of adhesion properties of polypropylene substrates by methyl methacrylate UV photografting surface treatment, Mater. Des., 33 (2012) 1-10.

[32] N.Y. Cui, D.J. Upadhyay, C.A. Anderson, B.J. Meenan, N.M.D. Brown, Surface oxidation of a Melinex 800 PET polymer material modified by an atmospheric dielectric barrier discharge studied using X-ray photoelectron spectroscopy and contact angle measurement, Appl. Surf. Sci., 253 (2007) 3865-3871.

[33] Y.K. Jung, T.Y. Kim, S.J. Park, S.Y. Lee, Metabolic Engineering of Escherichia coli for the Production of Polylactic Acid and Its Copolymers, Biotechnol. Bioeng., 105 (2010) 161171.

[34] M. Pascual, R. Sanchis, L. Sanchez, D. Garcia, R. Balart, Surface Modification of Low Density Polyethylene (LDPE) Film Using Corona Discharge Plasma for Technological Applications, J. Adhes. Sci. Technol., 22 (2008) 1425-1442.

[35] C.S. Ren, K. Wang, Q.Y. Nie, D.Z. Wang, S.H. Guo, Surface modification of PE film by DBD plasma in air, Appl. Surf. Sci., 255 (2008) 3421-3425.

[36] C.Q. Wang, X.N. He, Polypropylene surface modification model in atmospheric pressure dielectric barrier discharge, Surf. Coat. Technol., 201 (2006) 3377-3384.

[37] F. Leroux, C. Campagne, A. Perwuelz, L. Gengembre, Polypropylene film chemical and physical modifications by dielectric barrier discharge plasma treatment at atmospheric pressure, J. Colloid Interface Sci., 328 (2008) 412-420.

[38] J.X. Lei, X. Liao, Surface graft copolymerization of acrylic acid onto LDPE film through corona discharge, Eur. Polym. J., 37 (2001) 771-779.

[39] J.X. Lei, X. Liao, Surface craft copolymerization of 2-hydroxyethyl methacrylate onto lowdensity polyethylene film through corona discharge in air, J. Appl. Polym. Sci., 81 (2001) 28812887.

[40] K. Lachmann, B. Michel, C.P. Klages, Density and Aging Behavior of Primary Amino Groups on Afterglow Plasma-Treated Low-Density Polyethylene (LDPE), Plasma Process. Polym., 6 (2009) S401-S405.

[41] F. Truica-Marasescu, P.-L. Girard-Lauriault, A. Lippitz, W.E.S. Unger, M.R. Wertheimer, Nitrogen-rich plasma polymers: Comparison of films deposited in atmospheric- and lowpressure plasmas, Thin Solid Films, 516 (2008) 7406-7417.

[42] R.M. Rasal, D.E. Hirt, Micropatterning of Covalently Attached Biotin on Poly(lactic acid) Film Surfaces, Macromol. Biosci., 9 (2009) 989-996.

[43] R.M. Rasal, A.V. Janorkar, D.E. Hirt, Poly(lactic acid) modifications, Prog. Polym. Sci., 35 (2010) 338-356.

[44] R. Morent, N. De Geyter, C. Leys, L. Gengembre, E. Payen, Study of the ageing behaviour of polymer films treated with a dielectric barrier discharge in air, helium and argon at medium pressure, Surf. Coat. Technol., 201 (2007) 7847-7854.

[45] R.M. Thurston, J.D. Clay, M.D. Schulte, Effect of atmospheric plasma treatment on polymer surface energy and adhesion, J. Plast. Film Sheeting, 23 (2007) 63-78. 
[46] G. Borcia, C.A. Anderson, N.M.D. Brown, The surface oxidation of selected polymers using an atmospheric pressure air dielectric barrier discharge. Part II, Appl. Surf. Sci., 225 (2004) 186-197.

[47] M. Quitzau, M. Wolter, H. Kersten, Plasma Treatment of Polyethylene Powder Particles in a Hollow Cathode Glow Discharge, Plasma Process. Polym., 6 (2009) S392-S396.

[48] R. Sanchis, O. Fenollar, D. Garcia, L. Sanchez, R. Balart, Improved adhesion of LDPE films to polyolefin foams for automotive industry using low-pressure plasma, Int. J. Adhes. Adhes., 28 (2008) 445-451.

[49] I. Novak, G.K. Elyashevich, I. Chodak, A.S. Olifirenko, M. Steviar, M. Spirkova, N. Saprykina, E. Vlasova, A. Kleinova, Polymer matrix of polyethylene porous films functionalized by electrical discharge plasma, Eur. Polym. J., 44 (2008) 2702-2707.

[50] I. Novak, V. Pollak, I. Chodak, Study of surface properties of polyolefins modified by corona discharge plasma, Plasma Process. Polym., 3 (2006) 355-364.

[51] I. Novak, S. Florian, Influence of processing additives on adhesive properties of surfacemodified low-density polyethylene, Macromol. Mater. Eng., 289 (2004) 269-274.

[52] S. Guimond, M.R. Wertheimer, Surface degradation and hydrophobic recovery of polyolefins treated by air corona and nitrogen atmospheric pressure glow discharge, J. Appl. Polym. Sci., 94 (2004) 1291-1303.

[53] Y. Liu, Y. Fu, Inductively Coupling Plasma (ICP) Treatment of Propylene (PP) Surface and Adhesion Improvement, Plasma Sci. Technol., 11 (2009) 704-708.

[54] V. Takke, N. Behary, A. Perwuelz, C. Campagne, Studies on the Atmospheric Air-Plasma Treatment of PET (Polyethylene Terephtalate) Woven Fabrics: Effect of Process Parameters and of Aging, J. Appl. Polym. Sci., 114 (2009) 348-357.

[55] S.J. Lee, G. Khang, Y.M. Lee, H.B. Lee, The effect of surface wettability on induction and growth of neurites from the PC-12 cell on a polymer surface, J. Colloid Interface Sci., 259 (2003) 228-235.

[56] Y. Chen, L.N. Zhang, Y.S. Lu, C.S. Ye, L.B. Du, Preparation and properties of waterresistant soy dreg/benzyl konjac glucomannan composite plastics, J. Appl. Polym. Sci., 90 (2003) 3790-3796.

[57] M.O.H. Cioffi, H.J.C. Voorwald, L.R.O. Hein, L. Ambrosio, Effect of cold plasma treatment on mechanical properties of PET/PMMA composites, Compos. Pt. A-Appl. Sci. Manuf., 36 (2005) 615-623.

[58] M. Noeske, J. Degenhardt, S. Strudthoff, U. Lommatzsch, Plasma jet treatment of five polymers at atmospheric pressure: surface modifications and the relevance for adhesion, Int. J. Adhes. Adhes., 24 (2004) 171-177.

[59] S.J. Park, H.Y. Lee, Effect of atmospheric-pressure plasma on adhesion characteristics of polyimide film, J. Colloid Interface Sci., 285 (2005) 267-272.

[60] Y. Takemura, N. Yamaguchi, T. Hara, Study on surface modification of polymer films by using atmospheric plasma jet source, Jpn. J. Appl. Phys., 47 (2008) 5644-5647. 


\section{Table captions}

Table I. Contact liquids with its surface energy values and their polar and dispersive components.

Table II. Contact angle for different test liquids, with different aging times of a PLA treated sample with $6 \mathrm{~mm}$ reach and treatment rates of 100,300 and $700 \mathrm{~mm} \cdot \mathrm{s}^{-1}$.

Table III. Contact angles for different test liquids, in different aging times of a PLA sample treated to $10 \mathrm{~mm}$ and treatment rates of 100,300 and $700 \mathrm{~mm} \cdot \mathrm{s}^{-1}$.

Table IV: Values of shear strength of PLA/PLA adhesion joints for untreated PLA and PLA treated with atmospheric plasma.

\section{Figure legends}

Figure 1. Variation of the total surface energy $\left(\gamma_{s}\right)$ and polar contributions $\left(\gamma_{s}{ }^{p}\right)$ and dispersive $\left(\gamma_{s}{ }^{d}\right)$ of PLA substrate with different aging times for treated sample with a nozzle-sample distance of $6 \mathrm{~mm}$, treatment rate of $100 \mathrm{~mm} \cdot \mathrm{s}^{-1}(\mathrm{a}), 300 \mathrm{~mm} \cdot \mathrm{s}^{-1}(\mathrm{~b})$ and $700 \mathrm{~mm} \cdot \mathrm{s}^{-1}(\mathrm{c})$.

Figure 2. Variation of the total surface energy $\left(\gamma_{\mathrm{S}}\right)$ and polar contributions $\left(\gamma_{\mathrm{S}}{ }^{\mathrm{p}}\right)$ and dispersive $\left(\gamma_{S}{ }^{d}\right)$ of PLA substrate different aging times for a treated sample with a nozzle-sample distance of $10 \mathrm{~mm}$, with treatment rate of $100 \mathrm{~mm} \cdot \mathrm{s}^{-1}(\mathrm{a}), 300 \mathrm{~mm} \cdot \mathrm{s}^{-1}(\mathrm{~b})$ and $700 \mathrm{~mm} \cdot \mathrm{s}^{-1}(\mathrm{c})$.

Figure 3. Variation on the maximum shear strength on the PLA/PLA adhesion joints as a function of aging time, for PLA treated samples with a nozzle/substrate distance of $6 \mathrm{~mm}$ and treatment rates of 100,300 and $700 \mathrm{~mm} \cdot \mathrm{s}^{-1}$.

Figure 4. Variation on the maximum shear strength on the PLA/PLA adhesion joints, as a function of aging time, for PLA treated samples with a nozzle/substrate distance of $10 \mathrm{~mm}$ and treatment advance rates of 100,300 and $700 \mathrm{~mm} \cdot \mathrm{s}^{-1}$.

Figure 5. Image obtained from thermal camera for a nozzle/substrate distance of $6 \mathrm{~mm}$ and a treatment rate of $100 \mathrm{~mm} \mathrm{~s}^{-1}$.

Figure 6. Image obtained from thermal camera for a nozzle/substrate distance of $10 \mathrm{~mm}$ and a treatment rate of $100 \mathrm{~mm} \mathrm{~s}^{-1}$. 